\title{
Treatment Shaft for Combined Sewer Overflow Detention
}

\author{
Steven J. Wright ${ }^{1 *}$, Saad Ghalib², Aziz Eloubaidy ${ }^{3}$
}

\begin{abstract}
A deep, large-diameter underground shaft to provide detention storage for combined sewer overflow control may be advantageous in urban environments, where space limitations require solutions with a small footprint. An underflow baffle wall is provided at the center of the treatment shaft to prevent short-circuiting of the flow. An additional objective is to maintain low headlosses through the structure. A physical model study was conducted to determine the effect of the bottom elevation of the baffle wall on the headloss and breakthrough curve for dye injected to the inflow. It was found that there is a considerable range of elevations for which the structure behaves acceptably in providing adequate contact time for disinfectant while maintaining small headlosses. Water Environ. Res., 82, 434 (2010).
\end{abstract}

KEYWORDS: combined sewer overflow, detention, treatment, headloss, short-circuiting, baffle.

doi: $10.2175 / 106143009 X 426086$

\section{Introduction}

Increasingly strict regulations have been implemented in recent years to reduce the number and volume of overflows from combined sewer systems during rainfall events. A common approach to reduction of combined sewer overflows (CSOs) is to provide temporary storage to hold water until after the rainfall runoff subsides, after which, the storage facility can be dewatered by pumping back into the sanitary sewer system. Typical regulations specify the required hydrological event that storage is required to capture. Flow volumes that exceed the required storage are allowed to overflow to the receiving water body, but settling, skimming, screening, and disinfection generally are required before release. The detention facility also serves to remove solids from the overflow through sedimentation. For example, in the state of Michigan, the following specifications constitute adequate treatment of combined wastewater discharges to comply with water quality standards at times of discharge:

- Retention, for transportation and treatment at the wastewater treatment plant (WWTP), of combined wastewater flows generated during storms up to a 1-year return period, 1-hour duration storm;

\footnotetext{
${ }^{1}$ Civil and Environmental Engineering Department, University of Michigan, Ann Arbor, Michigan.

${ }^{2}$ NTH Consultants, Detroit, Michigan.

${ }^{3}$ Wade Trim and Associates, Detroit, Michigan.

* Civil and Environmental Engineering Department, University of Michigan, 113 EWRE, Ann Arbor, MI 48109-2125; e-mail: sjwright@ umich.edu.
}

- Primary treatment of combined wastewater flows generated during storms up to the 10-year, 1-hour storm (30-minute detention or equivalent for settling, skimming, and disinfection); and

- Treatment of combined wastewater flows generated during storms in excess of the 10-year, 1-hour storm, to the extent possible with facilities designed for lesser flows.

In addition to meeting regulatory compliance, an additional constraint on detention facility design is a limit on the hydraulic grade line upstream from the facility to prevent basement flooding resulting from sewer system backup. Therefore, it is necessary to ensure that diversion structures do not produce a significant backwater effect at design flow conditions.

Detention storage can be provided in a number of different ways, with design concerns associated with each alternative. One approach is to make use of in-system storage using real-time monitoring and control structures, such as gates or inflatable dams (Hudson, 1998), which can be operated to make maximum use of the storage available in the large-diameter sewer mains. One potential problem with this approach is that the harsh physical environment makes it difficult to ensure that moving components, such as gates and associated sensors, are functional when they are operated only on an intermittent basis. Another alternative is to provide offline detention basins, typically constructed belowgrade. These detention basins typically are designed using principles associated with traditional unit operations in WWTPs, such as sedimentation basins or clarifiers (Li et al., 2004; Metcalf \& Eddy, 2003). A major issue with this alternative is that the large required storage volumes dictate structures with a large footprint, which are difficult to locate in a densely populated urban environment. Still another solution has been the construction of deep storage tunnels that avoid space conflicts with shallow infrastructure by constructing the tunnel sufficiently far belowgrade, where other utilities are not located. A significant problem with long storage tunnels is that, when they are filled rapidly, the inertia of water rapidly filling the tunnel can result in significant surges, and air trapped during the filling process can result in the formation of "geysers" through access or ventilation shafts, with the result of either process being the potential to return lowquality water to grade (Guo, 1989; Guo and Song, 1990; Wright et al., 2006). Another problem is the removal of solids from a long tunnel once it has been dewatered (Dettmar and Staufer, 2005). A developed alternative that avoids many of these concerns is the treatment shaft. A treatment shaft is a detention basin, circular to take advantage of caisson construction technology, which is relatively small in footprint and achieves the required storage by extending to considerable depths below the ground surface. 
Because this is a relatively new concept in detention storage, information is generally lacking on hydraulic design aspects. This manuscript reports on an experimental investigation conducted to identify design elements to prevent short-circuiting in the flow through the treatment shaft and to prevent excess headlosses associated with the through-flow to reduce the probability of flooding upstream of the facility.

\section{Background}

The treatment shaft is a new patented technology (U.S. Patent No. 6,503,404; 7,341-670; other U.S. and international patents pending) that achieves the required CSO control and treatment as with the treatment basin, but with a much smaller footprint. This technology also provides skimming, settling, screening, and disinfection. Baffles and a partition provided within the shaft structure streamline the flow, to ensure sufficient disinfection contact time within the shaft and retain floatables. It also provides a very low upward flow velocity, which promotes settling. A screening facility at the effluent channel will eliminate objectionable material and sanitary trash from discharging to the receiving water body. Settled solids will be discharged to the sanitary sewer system following the rainfall events using solids handling pumps at the bottom of the shaft. Accumulated solids will be discharged with a chopper pump back into the interceptor for conveyance to the WWTP. A flushing system using high-pressure nozzles will clear the bottom of the shaft during a final rinse cycle. The treatment shaft has a low hydraulic head requirement to operate, which eliminates, in most cases, the need for a pump station. The treatment shaft technology is currently being implemented on the Dearborn (Michigan) CSO control projects.

More than one treatment shaft has been designed for the Dearborn system; the one studied in detail is referred to as CSO shaft 017 . Original designs intended to place the shaft in line by removing a section of the existing sewer (approximately a $4.3 \mathrm{~m} \times$ $5.5 \mathrm{~m}$ arch) and installing the shaft with upstream and downstream transitions to the existing sewer. Subsequent modifications to the original design resulted in a change of shaft location and required the construction of upstream and downstream sewer segments to tie the shaft to the existing system. Figures 1 and 2 provide schematics of the proposed shaft structure. Figure 1 depicts both plan and profile views of the proposed shaft, with inflow entering the structure from the conduit indicated on the left side of the drawing. Figure 2 is a cutaway view of the same structure from a different perspective. Here, the flow is indicated as entering from the right side of the diagram. Note the guide vanes in the inlet expansion; these were proposed to attempt to distribute flow uniformly across the inlet expansion in an attempt to minimize headlosses in the expanding flow. The floor of the shaft is not horizontal, but slopes down from the sides, to facilitate solids removal during dewatering operations. The slope is $2 \mathrm{H}: 1 \mathrm{~V}$ from an elevation of $135.3 \mathrm{~m}$ at the outside wall to $129.6 \mathrm{~m}$ at the central, flat portion of the floor. The proposed diameter of the treatment shaft is $29 \mathrm{~m}$, and the maximum depth of the structure is approximately $51 \mathrm{~m}$. Although the structure is covered, it is intended to flow with a free surface under normal operating conditions. During dry-weather flow conditions, water does not enter the shaft, but is carried through existing interceptors to the WWTP. In the event of a significant rainfall, the lack of capacity in the existing sewer system will cause overflow into the shaft. Smaller rainfall events will be contained entirely within the shaft, but, for greater inflows, the storage capacity of the shaft will be exceeded, and overflow will pass through the structure to a discharge point in the Rouge River.

Based on a pilot study, a 10-minute detention time within the structure was selected as sufficient to provide disinfection, which is achieved by the addition of sodium hypochlorite in the structure inlet. The sodium hypochlorite will be delivered at 12 to $15 \%$ concentration and diluted to approximately $5 \%$ before injection. The chlorine feed capacity is designed to provide a maximum chlorine dose rate of $25 \mathrm{mg} / \mathrm{L}$.

A key component of the treatment shaft design is a lateral baffle wall at the center of the shaft, which extends downwards from the top of the shaft. The inflow to the shaft must flow down under the baffle wall and up the other side. In addition to providing structural support for the shaft walls, a major function of the baffle wall is to prevent short-circuiting of the flow through the shaft. Baffles are a key component of common wastewater treatment units, such as sedimentation basins and activated sludge tanks, and in more typical detention treatment basins. The primary function is to ensure that the jet associated with the inflow does not bypass a significant portion of the storage volume (e.g., Kjellstrand et al., 2005). There is some guidance as to the design of baffles in more conventional rectangular basins that are typically longer than their widths or depths. The results of both numerical studies indicate that the placement and dimensions of the baffle wall are important to prevent short-circuiting and the retention of solids in suspension. Ahmed et al. (1996) observed, for example, that if the opening beneath the baffle wall is small, biosolids retention in a sedimentation basin is decreased, while the numerical studies of McCorquodale et al. (2007) and Sherwin and Ta (2002) suggest that there is an optimal baffle opening for solids retention. Because the geometries of the rectangular basins in these studies are substantially different than in a treatment shaft, any guidance provided by these previous studies is only qualitative. In addition, the geometry of the baffle wall may influence the hydraulic grade line upstream from the treatment shaft, because too small of an opening beneath the baffle wall will result in increased headloss and an unacceptable increase in hydraulic grade line. A physical model of the treatment shaft for CSO 17 was constructed and tested at design flow conditions to determine an acceptable geometrical configuration for the baffle wall.

\section{Experimental Setup}

A physical model at a scale of 1:19 (model:prototype) was constructed and tested using the dynamic similarity principles of Froude number equality in model and prototype. The model shaft was constructed from a large polyethylene tank with the baffle wall and other components constructed from polyvinyl chloride sheets. A typical model Reynolds number for the downflow within the shaft at a prototype flow of $41.2 \mathrm{~m}^{3} / \mathrm{s}$, for example, was approximately 22000 or well within the range of turbulent flow. Because the prototype shaft has not yet been constructed, all results presented below are the results of tests in the model. However, for clarity, all results are presented as scaled to the prototype structure. Key hydrological parameters include the following:

- The maximum discharge through the structure for the 5-year, 24-hour storm at average Rouge River levels is $52.9 \mathrm{~m}^{3} / \mathrm{s}$.

- The hourly average flow associated with the 10-year, 1-hour storm is $41.3 \mathrm{~m}^{3} / \mathrm{s}$.

- The maximum allowable upstream hydraulic grade line elevation at the inlet to the structure was established at 


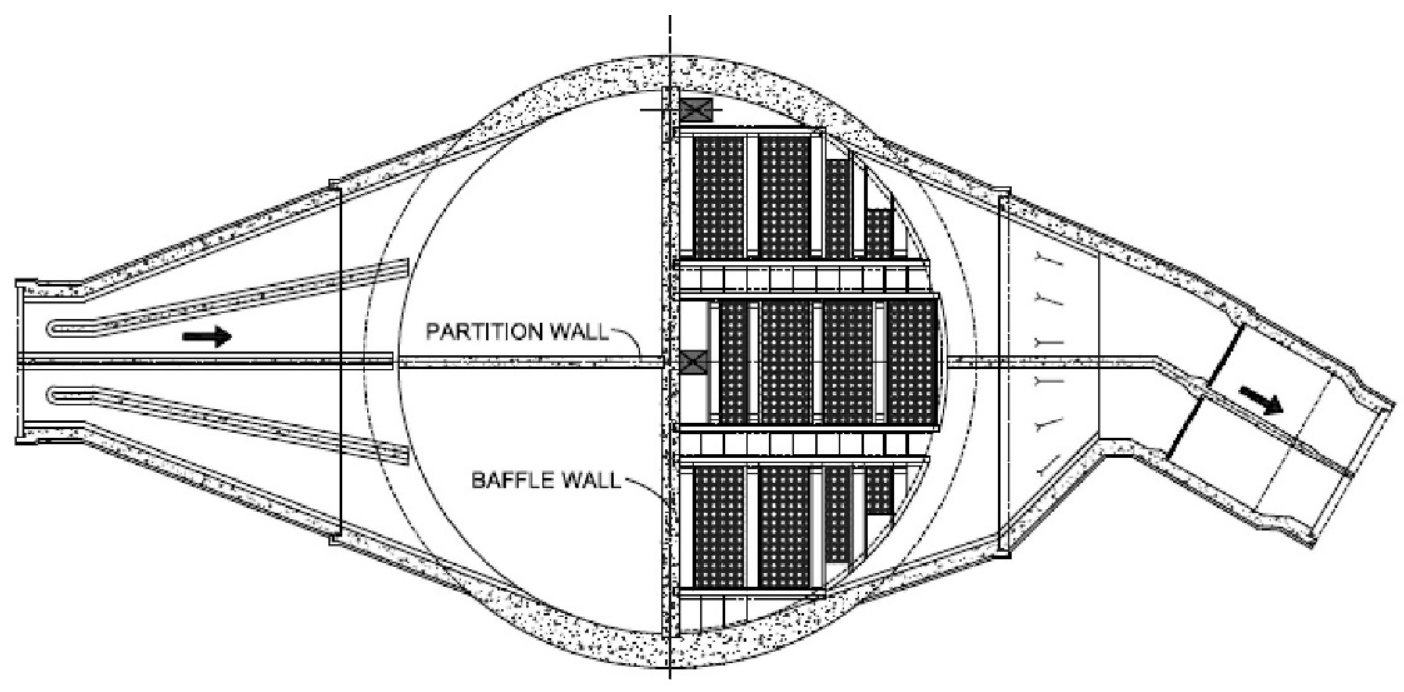

\section{PLAN}

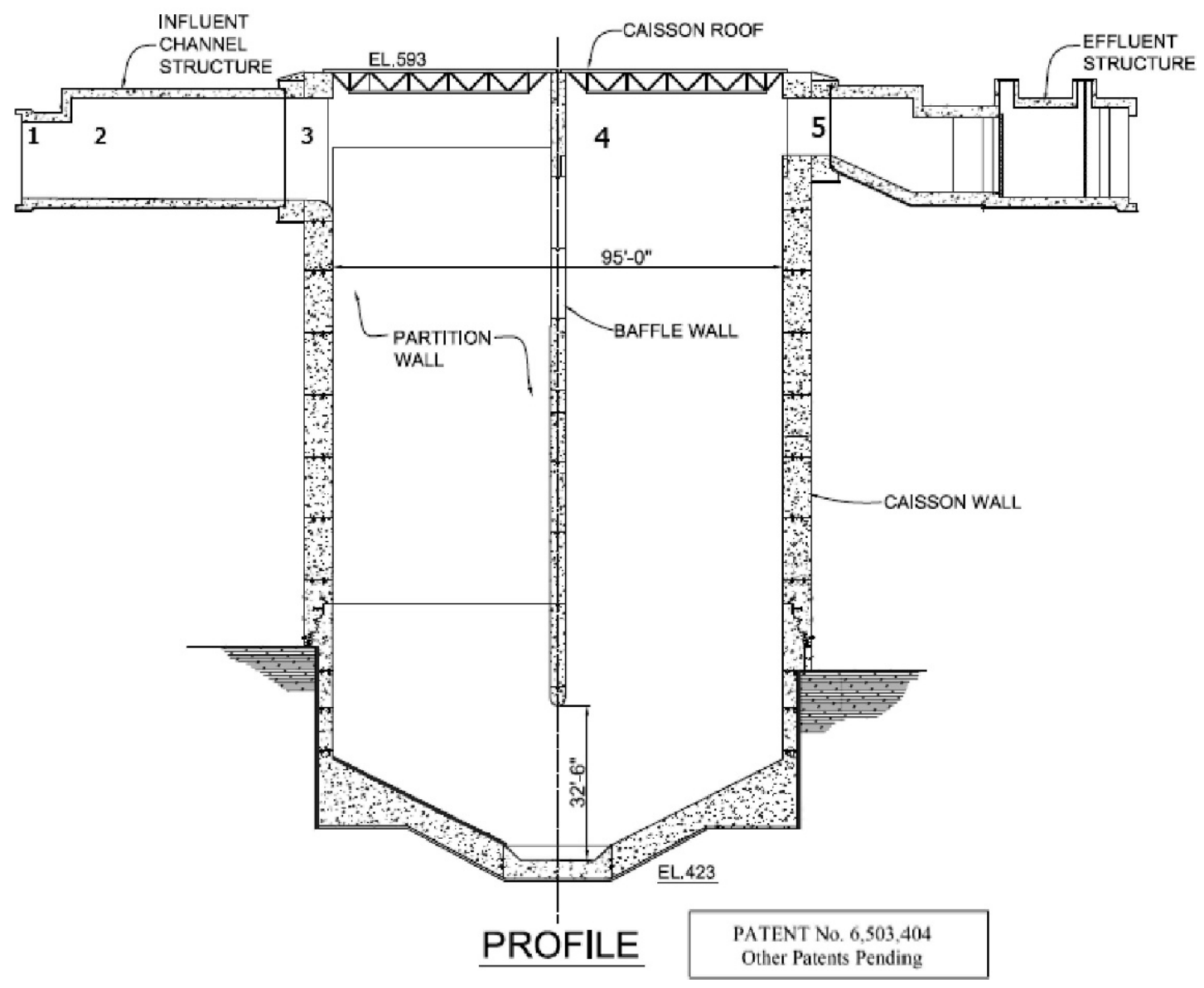

Figure 1-Plan and sectional view of proposed CSO treatment shaft no. 17. Patent nos. 6,503,404 and 7,341,670; other patents pending.

$177.8 \mathrm{~m}$ (amsl). The system is intended to maintain this condition at the discharge of $52.9 \mathrm{~m}^{3} / \mathrm{s}$.

At the 10-year flowrate, the upflow velocity through the prototype shaft will be approximately $0.125 \mathrm{~m} / \mathrm{s}$, corresponding to an overflow rate of approximately $11000 \mathrm{~m}^{3} /\left(\mathrm{m}^{2} \cdot \mathrm{d}\right)$, which is substantially greater than a typical value of $100 \mathrm{~m}^{3} /\left(\mathrm{m}^{2} \cdot \mathrm{d}\right)$ given by Metcalf \& Eddy (2003) for primary sedimentation tanks.

The model was constructed following dimensions developed in a preliminary design, with the exception of the bottom elevation 


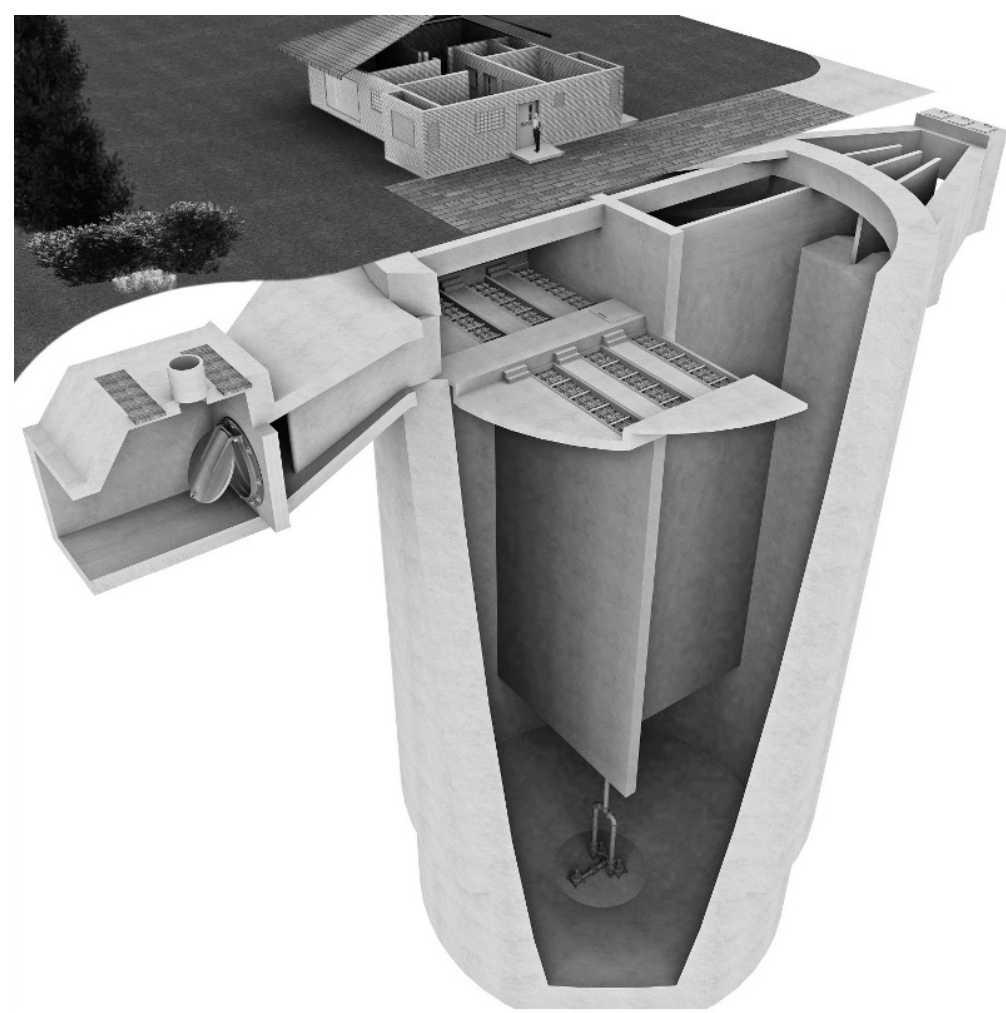

Figure 2-Cutaway rendition of proposed CSO treatment shaft no. 17. Patent nos. 6,503,404 and 7,341,670; other patents pending.

of the baffle wall that controlled the opening beneath the baffle wall. The baffle wall in the model was constructed such that it could slide in the vertical direction, allowing the bottom elevation to be continuously adjustable. The height of the inlet conduit increased at the entrance to the inlet expansion, resulting in an expansion of the flow at that location, resulting in a local headloss.

Hydraulic grade line elevations within the model were measured by means of point gauges installed in stilling wells connected to piezometer taps installed in the model at five locations. These locations are indicated on the profile section in Figure 1 as follows:

(1) Within the inlet conduit just before the beginning of the inlet expansion,

(2) Just into the inlet expansion,

(3) At the brink of the inlet expansion as the flow enters the shaft,

(4) On the immediate downstream side of the baffle wall, and

(5) At the beginning of the outlet conduit leaving the shaft.

Elevation differences were determined by referencing all point gauges to a common elevation established by damming the outlet channel and establishing a stagnant condition within the model. Estimated measurement uncertainty in the elevation differences between any two point gauges is on the order of a $2.5-\mathrm{cm}$ prototype dimension.

Flowrates through the model were measured with a venturi meter in the laboratory supply system. At the model flowrates, the measurement precision for the discharge is estimated to be $5 \%$. Assuming a quadratic relation between discharge and headloss, this uncertainty converts to an additional uncertainty in the headloss measurement that increases to approximately a $3.5-\mathrm{cm}$ prototype total.
Breakthrough performance was observed by measuring fluorescence in the outflow from the shaft. A sudden injection of Rhodamine B dye was initiated just upstream from the inflow expansion section, where flow-straightening baffles were installed to straighten the inflow. Visual observations of dye injections indicated that this was only partially successful. Outflow samples were collected in 7 -mL vials at 15 -second intervals, as the flow exited the shaft. These samples were obtained rapidly and are sufficiently small that turbulent fluctuations are not eliminated completely. The samples were analyzed in a GK Turner Model 110 fluorometer (Turner Designs, Mountain View, California), with the output adjusted to ensure that the injection concentration when mixed over the inflow resulted in a fluorometer reading of at least half of full-scale deflection. Breakthrough curves were measured until the dye concentration increased to the approximate value in the mixed inflow.

\section{Results}

System Headloss. A series of tests were performed to measure the headloss through the structure as a function of the baffle wall bottom elevation at the prototype design flow of $52.9 \mathrm{~m}^{3} / \mathrm{s}$. In each of these experiments, a downstream control gate installed in the model was adjusted to provide a hydraulic grade line elevation close to the maximum allowable of $177.8 \mathrm{~m}$ on the upstream side of the structure. The minimum bottom elevation tested for the baffle wall was $137.8 \mathrm{~m}$ (prototype dimension); this elevation is the minimum allowable to provide access clearance for flushing the shaft bottom after an inflow event. This baffle wall elevation corresponds to an underflow opening of approximately $8 \mathrm{~m}$. Testing was performed up to a maximum opening of $23.4 \mathrm{~m}$. Figure 3 presents the measured 


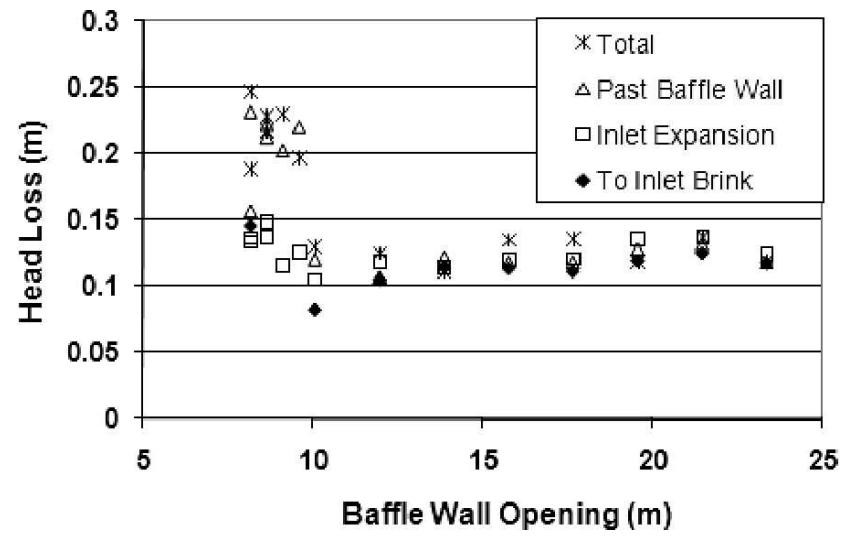

Figure 3-Hydraulic grade line changes from entrance of structure to selected locations as function of baffle wall underflow opening.

results over the range of baffle wall elevations tested. This figure presents results for the headloss measured from the influent channel (before the inlet expansion) to the outlet brink; little additional headloss would be expected in the gradually contracted flow to the outflow channel. The trend in the results is as expected; at low baffle wall elevations, the restricted flow beneath the baffle wall results in increased headlosses, while, at higher wall elevations, there is no significant effect on the headloss through the structure as the headloss across the baffle wall becomes negligible. Figure 3 indicates that the opening above which the variation in headloss is negligible is on the order of $9.9 \mathrm{~m}$. Variations in headloss for wall elevations above that level are within the measurement precision, and there is no apparent trend to these variations, indicating that the remaining headloss is concentrated in other parts of the structure. The average headloss for the data above that level is $0.126 \mathrm{~m}$. Once the baffle wall is lowered below the $9.9 \mathrm{~m}$ opening elevation, increases in headloss are apparent. Although there is some scatter in the data, these are within the estimated measurement precision discussed previously. The design elevation for the bottom of the baffle wall was set at an elevation of $139.6 \mathrm{~m}$ based on these findings, corresponding to an underflow opening of $10 \mathrm{~m}$. At that elevation, the flow area beneath the baffle wall is approximately $238 \mathrm{~m}^{2}$ or approximately $75 \%$ of the flow area in half the circular shaft (i.e., the flow area as the water goes down one side or up the other), resulting in only a small flow contraction beneath the baffle wall. An average velocity of $0.22 \mathrm{~m} / \mathrm{s}$ would be experienced for this flow area at the design flow of $52.9 \mathrm{~m}^{3} / \mathrm{s}$ and a velocity head of less than $0.01 \mathrm{~m}$, allowing for a contraction of the flow through the baffle wall. Therefore, it is reasonable to expect very small headloss for this flow condition.

Point gauge measurements were made at all five locations for most of the experiments, so that the distribution of headloss within the structure can be estimated; these results are presented in Figure 3 . With the very small headlosses measured and given the level of measurement precision, it is difficult to make definitive statements other than that most of the headloss for large baffle wall elevations was experienced in the inlet to the structure. There are two mechanisms that could contribute to this headloss; the first is the flow separation at each of the three divider walls within the inlet expansion, while the second is the sudden expansion loss resulting from the increase in the ceiling elevation passing from the inlet channel to the inlet expansion. An estimate of the sudden expansion loss associated with the increase in ceiling elevation (approximately $2 \mathrm{~m}$ from the inlet conduit crown elevation to the structure roof, but the design does not result in the structure flowing full, unless some combination of extreme inflow and flood elevation in the Rouge River occurs) yields a value of approximately $0.025 \mathrm{~m}$; it is less straightforward to estimate the losses associated with the leading edge of the divider walls. Nevertheless, the results in Figure 3 indicate negligible headloss within the shaft itself at large baffle wall elevations, but increasing as the baffle wall flow opening is reduced.

Dye Breakthrough. These experiments were all performed at a prototype discharge of $41.3 \mathrm{~m}^{3} / \mathrm{s}$ and an upstream hydraulic grade line elevation of approximately $177.1 \mathrm{~m}$, which was estimated to correspond to the limiting hydraulic grade line of $177.8 \mathrm{~m}$ at the higher flowrate of $52.9 \mathrm{~m}^{3} / \mathrm{s}$. A total of 15 individual runs were made. These experiments included varying the baffle wall bottom elevation between $139.6 \mathrm{~m}$ (to stay above the level where headloss begins to increase) and $156.4 \mathrm{~m}$.

It is difficult to ascertain a difference between the various experiments. Conclusions are somewhat complicated by the turbulent fluctuations in dye concentration, but the experimental results are consistent. The experiments were initiated by opening a valve controlling the dye inflow to the model supply pipe just upstream from the modeled inlet chamber. The intention was to gain mixing from the redirection of the inflow from the pipe into the actual model section. Because the injection was at a very low rate from a concentrated dye solution, the injection did not contribute significantly to the actual system flow. Observations made of dye inflow to the model showed that there was not a sharp dye front entering the model structure, and complete initial mixing in the inflow was not achieved. Therefore, the observed width of the breakthrough curve is partially the result of the method of dye injection. Dye samples were collected at the outlet at 15 -second intervals over a total injection interval of 6 minutes. This length of dye injection resulted in a fairly constant dye concentration for the last 1 or 2 minutes of the sampling interval. All results presented are in terms of a ratio $C / C_{\mathrm{o}}$, in which $C$ is the instantaneous dye concentration, and $C_{\mathrm{o}}$ is the final steady-state dye concentration defined from the average concentration of the last six samples collected in any one experiment. In this format, relative dye concentrations should vary from 0 , at the beginning of an experiment, to 1 , at the completion of the experiment. In some cases, the experiments were performed by injecting dye at the beginning of the experiment for 6 minutes and continuing sampling at the 6-minute point when the dye injection was shut off. In those particular experiments, the relative concentration $1-$ $C / C_{\mathrm{o}}$ following dye shutoff should be consistent with all other experiments. One of these experiments is included in the results presented in Figure 4, with the indicated time corresponding to the observed time in the model scaled up to prototype times by multiplying by a factor of (19) ${ }^{1 / 2}$ required with the assumption of Froude Number dynamic similarity. Essentially three repetitions are presented-one performed with sampling after the dye injection was shut off (labeled "End Dye Injection") and two performed in the conventional manner (labeled "Dye Injection"). The results from the three experiments are basically consistent with each other, discounting for small differences in individual runs resulting from turbulent fluctuations. If the mean breakthrough time is taken as the time at which $C / C_{\mathrm{o}}=0.5$, the 


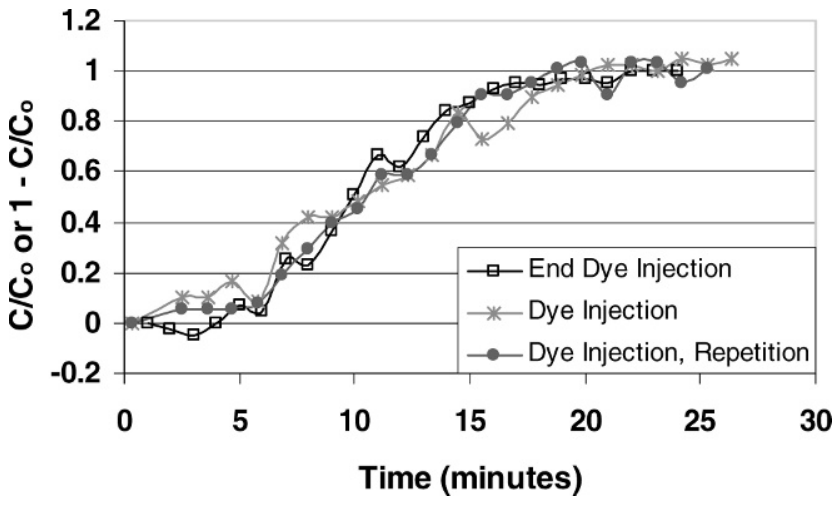

Figure 4-Fluorescent dye breakthrough curves for multiple repetitions of same baffle wall configuration and discharge.

prototype contact time implied by these experiments is estimated at approximately 11 minutes. Attempting to estimate the volume of water in the structure at this flow condition and dividing by the flowrate yields a retention time of approximately 11.5 minutes. The differences between these two values are at approximately the limit of the ability to measure the discharge and to interpret the breakthrough curve. There is no indication of any significant dead zones associated with the flow through the shaft, but there is dispersion of the injected dye.

Results for the breakthrough curves for four different baffle wall openings are presented in Figure 5. Although results were obtained for additional baffle wall elevations, these four are representative of the range of baffle wall elevations tested. At the very highest baffle wall openings (above $26.8 \mathrm{~m}$ ), there may be a slight tendency for the breakthrough curves to be altered, although it is difficult to make that conclusion, as a result of the turbulent fluctuations in the concentration curves.

\section{Conclusions}

The concept of the treatment shaft was developed as a means of avoiding potential construction or operational difficulties associated with more conventional detention systems, such as storage tunnels or retention treatment basins. The small footprint of the structure provides some significant advantages, such as ease in solids removal. Also, the very low velocities through the structure provide negligible flow inertia, eliminating the potential for undesirable surges. Operational questions identified for the treatment shaft related to the headloss associated with flow through the structure and the possibility of short-circuiting of flow through the shaft. An underflow baffle wall was included in the design to prevent flow short-circuiting. A scale model study was conducted to study the required baffle wall opening that would provide small headlosses, while minimizing short-circuiting.

The physical model was tested at the design flow condition by adjusting the opening beneath the baffle wall and measuring the change in hydraulic grade line elevation across the structure. It was observed that, for baffle wall openings in excess of a certain value, the headloss across the structure became independent of the height of the opening; for the design tested, this opening was approximately $10 \mathrm{~m}$. Improvements in the entrance conditions at the structure inlet could possibly reduce the headloss further; however, because the structure met the design constraints on

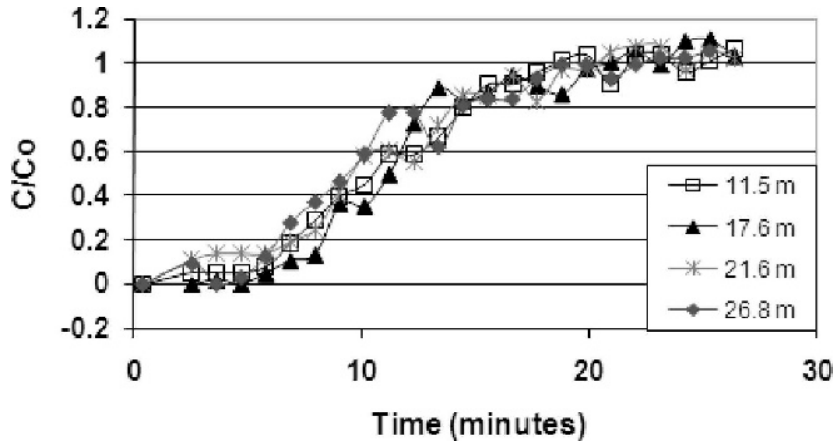

Figure 5-Fluorescent dye breakthrough curves as a function of baffle wall underflow opening.

headloss with the original design, no attempts to modify the proposed design were made.

The physical model then was subjected to further testing with dye injection, to observe the breakthrough of dye through the structure. The baffle wall opening was increased over $5 \mathrm{~m}$ above the level required to maintain a minimum structure headloss, with no discernable changes in the dye breakthrough curves. The baffle wall position was selected as the lowest level feasible while still maintaining acceptable system headlosses, but there is a considerable range of baffle wall openings that would meet the design constraints.

Submitted for publication July 29, 2008; revised manuscript submitted October 17, 2009; accepted for publication October 22, 2009.

\section{References}

Ahmed, F. H.; Kamel, A.; Jawad, S. A. (1996) Experimental Determination of Optimal Location and Contraction of Sedimentation Tank Baffles. Water Air Soil Pollut., 92, 251-271.

Dettmar, J.; Staufer, P. (2005) Modelling of Flushing Waves for Optimized Cleaning Operations. Water Sci. Technol., 52 (5), 233-240.

Guo, Q. (1989) Geysering in Urban Storm Drainage Systems. Proceedings of the XXIII Congress of the International Association on Hydraulic Research; National Research Council Canada: Ottawa, Canada, S75$\mathrm{S} 81$.

Guo, Q.; Song, C. S. S. (1990) Surging in Urban Storm Drainage Systems J. Hydraul. Eng., 116 (12), 1523-1537.

Hudson, D. M. (1998) Inflatable Gates Improve Storage, Reduce CSO. Public Works, 129 (9), 54-59.

Kjellstrand, R.; Mattson, A.; Niklasson, C.; Tarzadeh, M. J. (2005) Short Circuiting in a Denitrifying Mixing Tank. Water Sci. Technol., 52 (10-11), 79-87.

Li, J. G.; Horneck, H.; Averill, D.; McCorquodale, J. A.; Biswas, N. (2004) High-Rate Retention Basins for CSO Control in Windsor, Ontario. Water Qual. Res. J. Can., 39 (4), 449-456.

McCorquodale, J. A.; Griborio, A.; Li, J. G.; Hornbeck, H.; Biswas, N. (2007) Modeling a Retention Treatment Basin for CSO. J. Environ. Eng., 133 (3), 263-270.

Metcalf \& Eddy (2003) Wastewater Engineering: Treatment and Reuse, Tchobanoglous, G., Burton, F. L., Stensel, H. D. (Eds.); McGrawHill: New York.

Sherwin, C.; Ta, C. T. (2002) Investigation of Anaerobic Zone ShortCircuiting Using Computation Fluid Dynamics. Water Sci. Technol., 46 (4), 333-338.

Wright, S. J.; Lewis, J. W.; Vasconcelos, J. G. (2006) Mechanisms for Stormwater Surges in Vertical Shafts. Chapter 5, Monograph 15, Contemporary Modeling of Urban Water Systems. James, W. (Ed.); CHI Inc.: Guelph, Ontario, Canada. 